\title{
Construction of novel cGMP FRET-sensors based on PKG from Plasmodium falciparum
}

\author{
Gaia Calamera ${ }^{1,2}$, Andrea Hembre Ulsund ${ }^{1,2}$, Ornella Manfra ${ }^{1,2}$, Jeong Joo Kim³ ${ }^{3}$ Choel Kim³, Finn Olav Levy ${ }^{1,2}$, \\ Kjetil Wessel Andressen ${ }^{1,2^{*}}$
}

From 7th International Conference on cGMP Generators, Effectors and Therapeutic Implications

Trier, Germany. 19-21 June 2015

\section{Background}

Several sensors for cyclic nucleotides have been developed the past decade. However, there are few sensors for cGMP available and even fewer that detect low concentrations of cGMP. Currently, only the CFP/YFP sensors Cygnet 2.1, cGES-DE5 and cGi-500 (EC50 $\sim 1.7 \mu \mathrm{M}, 1.5 \mu \mathrm{M}$ and $500 \mathrm{nM}$, respectively) and the T-sapphire/Dimer2 sensor Red cGES-DE5 (EC50 $\sim 40 \mathrm{nM}$ ) are available [1-3]. We aim to measure localized pools of cGMP in single adult cardiac myocytes, and have previously found that such sensors should have an EC50 less than $50 \mathrm{nM}$, thus excluding the CFP/YFP sensors above. The Red cGES-DE5 has an acceptable EC50, but tagging this sensor to locate in distinct compartments within cardiac myocytes yielded sensors with a smaller dynamic range. We therefore decided to construct new FRET-based cGMP-sensors with high affinity for cGMP that could be better candidates for subcellular localization.

\section{Methods}

Based on the recent crystallization of Plasmodium falciparum cGMP-dependent Protein Kinase [4], sensors for cGMP were constructed using the cyclic nucleotide-binding domain D flanked with different FRETpairs (either CFP/Citrine or T-sapphire/Dimer2) in its $\mathrm{N}$ - and $\mathrm{C}$-terminal to generate two different sensors for cGMP, excitable at various wavelengths. Sensors were then expressed in HEK293 cells and their activity tested in vitro by measuring FRET upon addition of cGMP.

\section{Results}

Sensors with high affinity for cGMP (EC50 of $26 \pm 14 \mathrm{nM}$ ) were constructed. We also determined that the affinity for cAMP was almost 50 fold lower $(1 \pm 0.5 \mu \mathrm{M})$.

\section{Conclusion}

We have constructed FRET-based cGMP sensors with high affinity for cGMP that can be utilized in single cells when concentrations of cAMP are less than $0.1 \mu \mathrm{M}$.

\section{Authors' details}

'Department of Pharmacology, University of Oslo and Oslo University Hospital, Oslo, Norway. ${ }^{2}$ K.G. Jebsen Cardiac Research Centre and Center for Heart Failure Research, University of Oslo, Oslo, Norway. ${ }^{3}$ Department of Pharmacology, Baylor College of Medicine, Houston, TX, USA.

Published: 2 September 2015

\section{References}

1. Nikolaev VO, Gambaryan S, Lohse MJ: Fluorescent sensors for rapid monitoring of intracellular cGMP. Nat Methods 2006, 3(1):23-25.

2. Russwurm M, Mullershausen $F$, Friebe $A$, Jäger $R$, Russwurm $C$, Koesling $D$ : Design of fluorescence resonance energy transfer (FRET)-based CGMP indicators: a systematic approach. Biochem J 2007, 407(1):69-77.

3. Niino $Y$, Hotta K, Oka K: Simultaneous Live Cell Imaging Using Dual FRET Sensors with a Single Excitation Light. PLoS One 2009, 4(6):e6036.

4. Kim JJ, Flueck C, Franz E, Sanabria-Figueroa E, Thompson E, Lorenz R, et al: Crystal Structures of the Carboxyl cGMP Binding Domain of the Plasmodium falciparum cGMP-dependent Protein Kinase Reveal a Novel Capping Triad Crucial for Merozoite Egress. PLoS Pathog 2015, 11(2): e1004639.

doi:10.1186/2050-6511-16-S1-A34

Cite this article as: Calamera et al:: Construction of novel cGMP FRETsensors based on PKG from Plasmodium falciparum. BMC Pharmacology and Toxicology 2015 16(Suppl 1):A34.

\footnotetext{
* Correspondence: k.w.andressen@medisin.uio.no

'Department of Pharmacology, University of Oslo and Oslo University

Hospital, Oslo, Norway

Full list of author information is available at the end of the article
} 